\title{
Unidade de ação: um desafio para a enfermagem brasileira
}

\author{
Jorge Lorenzetti \\ Denise Elvira Pires de Pires ${ }^{2}$ \\ Jonas Spricigo ${ }^{3}$ \\ Soraia Dornelles Schoeller ${ }^{4}$
}

INTRODUÇÃO

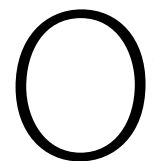
O presente paper foi elaborado por sujeitos que vivenciaram a organização do Movimento Participação (MP) na enfermagem brasileira e a efervescência dos movimentos sociais dos anos 1980. Tem por objetivo defender a importância da unidade de ação para a construção de um projeto coletivo de fortalecimento profissional e de intervenção no setor saúde.

As reflexões formuladas foram instigadas pela análise do cenário do setor saúde e da enfermagem nesta segunda década do século 21; pelo balanço de perdas e ganhos da profissão nos últimos 32 anos; e pelo desejo de contribuir para a construção de caminhos para a valorização da enfermagem nos próximos 50 anos.

\section{A ENFERMAGEM NO CENÁRIO DOS ANOS 1980}

A década de 1980 foi muito especial no Brasil. A população, através de organizações sociais, ampliou as ações políticas do final dos anos 1970 e foi às ruas e praças reivindicar o fim da ditadura militar, democracia, melhores condições de vida e justiça social. Ainda sob a ditadura militar até 1984, os movimentos sociais reorganizaram-se articulando diversos segmentos da sociedade brasileira lutando por direitos de cidadania e, dentre eles, pelo direito à saúde. Destaca-se, no período, a organização do movimento de mulheres com significativa participação nas lutas de caráter classista e também apresentando demandas específicas, relativas à condição feminina ${ }^{(1)}$.

A enfermagem brasileira não ficou omissa e, mesmo com alguma timidez, contribuiu para as conquistas gerais da sociedade. Ao mesmo tempo, buscou avançar nas suas necessidades específicas enquanto um importante contingente de trabalhadores do setor saúde. O Movimento Participação, nascido, crescido e consolidado nos anos 1980 é a marca da enfermagem naquele contexto histórico(1).

O saldo da década foi muito positivo. Conquista-se o fim da ditadura militar, institui-se uma Assembleia Nacional Constituinte que aprova, em 1988, a Constituição em vigor, denominada de cidadã pelo reconhecimento de direitos sociais, dentre eles o direito universal à saúde, e por criar o Sistema Único de Saúde, regulamentado pelas Leis 8880 e 8142 de 1990(1).

\section{BALANÇO DE GANHOS E PERDAS DAS LUTAS DOS ANOS 1980}

Olhar para a história é sempre um ensinamento e inspira reflexões críticas. Uma retrospectiva dos anos 1980 permite encontrar ganhos da enfermagem brasileira, fruto das lutas e mobilizações, tendo como convergência o Movimento Participação. Destaca-se como conquista a democratização das entidades e seu fortalecimento como espaço de representação da profissão na sociedade: muda a postura de submissão às políticas governamentais e aos interesses das empresas multinacionais do setor saúde, inicia-se uma atuação crítica e proativa de formulação de políticas para o setor saúde e enfermagem, estimula-se a participação da categoria nos processos decisórios e muda o caráter dos eventos da ABEn, que passam a abordar, além de aspectos técnico-científicos, questões político-profissionais, condições de trabalho, política de saúde e a situação do país ${ }^{(1)}$.

A mobilização da categoria possibilita a aprovação da Lei do Exercício Profissional (Lei 7498/86), que determina a profissionalização da maioria dos trabalhadores de enfermagem da época (os atendentes de enfermagem), prescreve a necessidade da Sistematização da Assistência de Enfermagem e a presença de enfermeiros/as em todas as instituições de saúde em que a enfermagem atua.

Esses ganhos das lutas dos anos 1980 são inegáveis, e importantes, mas é necessário refletir sobre as oportunidades históricas não aproveitadas ou aproveitadas de forma tímida e limitada.

A estratégia central do Movimento Participação foi a defesa da valorização da enfermagem, a partir de um diagnóstico, amplamente aceito, de que a enfermagem tinha uma enorme responsabilidade nas ações e resultados dos serviços de saúde (de cada 100 ações, cerca de 60 eram de responsabilidade da

1 Enfermeiro, Ddo do Programa de Programa de Pós-Graduação em Enfermagem da Universidade Federal de Santa Catarina, UFSC. Professor do Departamento de Enfermagem. Membro do Grupo de Pesquisa “PRAXIS: trabalho cidadania, saúde e enfermagem". Presidente da ABEn-SC - 1980-1984.

2 Enfermeira, Doutora em Ciências Sociais (UNICAMP), Pós-Doutorado na University of Amsterdam, Holanda. Professora da UFSC, Departamento e Programa de Pós-Graduação em Enfermagem. Pesquisadora CNPq, membro do Grupo de Pesquisa PRAXIS. Presidente da ABEn-SC - 1986-1989. Presidente do Coren-SC 2008-2011.

3 Enfermeiro, Doutor em Filosofia da Enfermagem pelo Programa de Programa de Pós-Graduação em Enfermagem da UFSC. Professor da UFSC, Departamento de Enfermagem. Presidente da ABEn-SC - 1984-1986.

4 Enfermeira, Doutora em Filosofia da Enfermagem pelo Programa de Programa de Pós-Graduação em Enfermagem da UFSC. Professora da UFSC, Departamento de Enfermagem, membro do Grupo de Pesquisa PRAXIS. 
enfermagem). No entanto, convivia com pouca valorização e reconhecimento do seu trabalho, em especial, no que dizia respeito às condições de trabalho, remuneração digna e autonomia profissional.

Nos últimos 32 anos, o Brasil mudou muito. A população passou de 119.002.706, em 1980, para 190.732.694 de brasileiros em 2010(2), o direito à saúde é um valor reconhecido e o SUS é uma realidade, mas carece de consolidação.

A enfermagem, nesse período, cresce em número e qualificação e continua sendo, de longe, o maior contingente de trabalhadores da saúde.

No entanto, em relação à valorização e condições de trabalho
O momento é muito favorável porque no Brasil e no mundo a população tem colocado a saúde no topo da pirâmide de prioridades. E o trabalho da enfermagem tem forte impacto na qualidade da assistência em saúde.

Nesse contexto, ousamos apresentar alguns objetivos estratégicos, na esperança de que lideranças da enfermagem, atuais e futuras, obtenham novas e necessárias conquistas para a profissão e a saúde.

\section{REORIENTAR A PRÁTICA PROFISSIONAL DA ENFERMAGEM}

Infelizmente, a enfermagem ainda está fortemente referenciada pelo modelo biomédico, centrado no hospital, no médico e na doença, e menos por um modelo voltado para a promoção da saúde, da integralidade e usuário centrado.

A enfermagem não pode ser responsabilizada pelas mazelas da saúde no Brasil, mas é parte dos problemas. Queremos ressaltar que

Quadro 1 - População da Enfermagem, Brasil: 1983- 2010.

*Segundo a Pesquisa Cofen(4): 106 parteiras e 3.073 trabalhadores registrados sem especificação do grau de formação.

tivemos poucos avanços. Outros grupos sociais aproveitaram muito melhor a oportunidade histórica dos anos 1980. Lutaram por um Brasil mais justo e solidário, aliando lutas por melhores condições de vida e trabalho com a criação e consolidação de entidades nacionais fortes, representativas e protagonistas dos interesses dos seus associados.

A enfermagem perdeu uma grande oportunidade histórica de construção de uma entidade unitária que impulsionasse um projeto nacional da profissão, integrando as dimensões técnico-científicas e de condições de trabalho requeridas para uma assistência de enfermagem segura e de qualidade. Some-se a isso, um longo período de descaminhos e práticas vergonhosas no sistema Cofen/ Conselhos Regionais.

\section{UNIDADE DE AÇÃO - UMA NOVA OPORTUNIDADE HISTÓRICA}

A mensagem do início dos anos 2010 é de um novo período promissor que não pode ser perdido.

O sistema Cofen/Conselhos Regionais retoma um alinhamento com os valores de participação, democracia e defesa dos interesses da enfermagem brasileira. Constrói-se uma nova aliança entre as entidades da enfermagem (Cofen, $A B E n, F N E$, sindicatos e associações diversas que representam a enfermagem) em torno de objetivos concretos, como a regulamentação da jornada de 30 horas semanais, mas que pode avançar para uma articulação permanente e sistemática de construção de um projeto estratégico para a enfermagem brasileira. Vivemos outra oportunidade histórica de articular unidade de ação em defesa da profissão, do direito à saúde e de cuidados de enfermagem de qualidade. a enfermagem pode ser a diferença como agente de mudanças.

Uma reorientação da prática profissional da enfermagem, redirecionando o foco paraum compromissoe responsabilização com as necessidades de saúde das pessoas poderá levar a ganhos incomensuráveis para a melhoria da assistência e para a profissão. Destacando-se o desenvolvimento de conhecimentos e tecnologias profissionais e a conquista de condições dignas de trabalho, um déficit crônico da sociedade para com a enfermagem.

PRIORIZAR A CONSOLIDAÇÃO DO SUS O SUS conquistado está longe de se consolidar em sua missão de assegurar uma atenção de saúde para todos, de forma universal, integral, equânime, descentralizada, resolutiva, gratuita, de qualidade e com controle social. Não se trata de uma utopia, mas de um objetivo estratégico a ser perseguido para e pelos brasileiros. Para tanto, é indispensável assegurar um financiamento adequado e estável (política de Estado), universalizar a Atenção Básica $(A B)$ e construir a rede própria do SUS de média e alta complexidade, além de impulsionar uma gestão apropriada para a complexidade da administração de redes e do trabalho multiprofissional, com atuação interdisciplinar, numa compreensão ampliada do direito a saúde ${ }^{(5)}$.

O SUS é um belo projeto incompleto. Consolidar o SUS é parte importante da construção de um Brasil mais justo e solidário. A enfermagem pode e deveria jogar um papel relevante na consolidação do SUS face à quantidade $\mathrm{e}$ qualidade dos cuidados prestados à população, em todos os níveis e complexidade dos serviços.

A enfermagem tem participação significativa no cuidado aos 
brasileiros e "desde o acolhimento em todas as unidades da rede de serviços até os tratamentos mais complexos, tece os fios das linhas de cuidados, assistindo, gerenciando e orientando"(5:2).

A consolidação do SUS precisa e depende da enfermagem. E a enfermagem depende da consolidação do SUS para um exercício profissional comprometido e valorizado.

Pode-se estimar que, atualmente, cerca de $15 \%$ dos/as enfermeiros/as brasileiros/ as atuam na Atenção Básica, diretamente no SUS. E, se considerarmos os diversos serviços do SUS e as unidades privadas que prestam serviços ao SUS, mais de $80 \%$ da enfermagem brasileira trabalha relacionada ao SUS.

\section{ELABORAR, DEFENDER E CONQUISTAR UM PLANO NACIONAL DE CARREIRA DA ENFERMAGEM NO CONTEXTO DO SUS}

Os servidores públicos aproveitaram o processo de luta dos anos 1980, organizaram entidades amplas e representativas e conquistaram Planos Nacionais de Carreiras Profissionais (professores do ensino superior, previdenciários e muitas outras categorias na esfera municipal, estadual e federal).

O SUS é um sistema público de saúde que envolve essas esferas e prestadores de serviço do setor privado. Daí a relevância e pertinência da indicação deste objetivo estratégico para a enfermagem brasileira.

Condições dignas de trabalho, remuneração e aposentadoria para a enfermagem precisam constar de um Plano Nacional de Carreira no SUS, que passaria a ser referência para todos os profissionais e serviços de saúde.

\section{AMPLIAR A PROFISSIONALIZAÇÃO NA ENFERMAGEM}

Neste ano de 2012 o Governo Federal tem anunciado medidas para ampliar a formação de médicos, pois a falta deles seria um dos gargalos do SUS. Se compararmos com os países mais desenvolvidos, é certo que o Brasil precisa de mais médicos e leitos hospitalares. O que não aparece é o fato de que também há carência de profissionais de enfermagem.

Tomando-se como base a referência de 30 países da Organização para a Cooperação e Desenvolvimento Econômico (OCDE), de 2007, em média, 3,1 médicos e 9,6 enfermeiros/ as por 1.000 habitantes, o Brasil teria um déficit de 234.558 médicos (considerando-se os 356.713 médicos registrados no CFM, 2010) e de 390.024 profissionais de enfermagem (calculados em relação à população apurada no censo do IBGE de 2010). Cabe registrar que desse total, o maior déficit é de enfermeiros/as, correspondendo a $385.636^{(5)}$.

Esse déficit é um indicativo de provável sobrecarga de trabalho e fator relevante nas dificuldades de acesso para a população obter atendimento adequado na rede de serviços, em especial de média e alta complexidades, um reconhecido gargalo do SUS.
A profissionalização dos atendentes de enfermagem foi uma iniciativa importante e de impacto. Por que não propor agora a suspensão da formação de novos auxiliares de enfermagem estimulando a formação dos atuais como técnicos/as ou enfermeiros/as? A equipe de enfermagem ficaria mais qualificada para a assistência com redução da fragmentação e influência positiva na qualidade da assistência e ambiente de trabalho.

\section{FORMAÇÃO DE LIDERANÇAS UM DESAFIO PREMENTE}

O caminho para a conquista destes e outros objetivos estratégicos exige um amplo e permanente programa de capacitação em liderança para enfermeiros/as e técnicos de enfermagem.

A experiência realizada pelo Coren-SC e ABEn-SC, em 2011, de um curso de capacitação avançada de liderança mostrou, nitidamente, que essa é uma grande lacuna e uma necessidade de prioridade máxima a ser desenvolvida para um futuro melhor para a enfermagem brasileira. Enfermeiras/os líderes são a esperança para o presente e futuro de uma profissão tão essencial ao ser humano.

Os líderes da enfermagem têm, neste momento histórico, a grande responsabilidade de construir uma efetiva, estável, forte e permanente unidade de ação para a conquista de necessidades relevantes e estruturais.

\section{Referências}

1. Lorenzetti J, Pires DEP, Sprícigo J. Movimento participação, um marco

na história da ABEn. Anos 1980 na ABEn-SC. In: A trajetória da Associação

Brasileira de Enfermagem - Seção Santa Catarina, 2012. (no prelo).

2. IBGE. Censo 2010 [Internet]. [citado em 2012 Jun 20]. Disponível em:

http://www.ibge.gov.br/censo2010/

3. Associação Brasileira de Enfermagem. Conselho Federal de Enfermagem.

Força de trabalho de enfermagem: o exercício da enfermagem nas

instituições de saúde do Brasil 1982/1983. Rio de Janeiro: Cofen; 1985.

4. Barreto IS, Krempel MC, Humerez DC. O Cofen e a enfermagem na

América Latina. Rev Enferm Foco. 2011;2(4):251-4.

5. Lorenzetti J. A enfermagem e os desafios para a saúde no Brasil:

propostas para o período 2011-2015. Florianópolis; [Internet]. [citado

em 2012 Jun 20]. Disponivel em: http://www.corensc.gov.br/thumbs/file/

documentoenfermagem.pdf 